Open Access

\title{
Analysis of livelihood activity amongst itinerant west African migrant traders in the Accra metropolitan area
}

\author{
Elijah Yendaw ${ }^{1 *}$, Augustine Tanle ${ }^{2}$ and Akwasi Kumi-Kyereme ${ }^{2}$
}

\author{
* Correspondence: \\ eyendaw@uds.edu.gh \\ ${ }^{1}$ Department of Governance and \\ Development Management, Faculty \\ of Planning and Land Management, \\ University for Development Studies, \\ Wa, Ghana \\ Full list of author information is \\ available at the end of the article
}

\begin{abstract}
In West Africa, studies on migration and livelihoods are mostly limited to internal migrants. This study analyzed the livelihood activities of itinerant West African migrant traders in the Accra Metropolitan Area, using mixed methods approach. The study which was guided by the framework for migration and itinerant migrant trade surveyed 779 itinerant immigrant traders and interviewed 12 key informants. Descriptive statistics and binary logistic regression were the main analytical techniques used. The results showed that most of the immigrant traders were young, unmarried males with no formal education and their main trading activity was itinerant retailing of foot wears/leather belts/bags and herbal medicines. As regards their livelihood status, female immigrant traders and those who were younger (<20 years) were less likely to have improved livelihood status. Moreover, while immigrant traders of food products were more likely to have a deteriorated livelihood status, those engaged in the sale of durable products (electronics and accessories) were most likely to achieve improved livelihood status. The study recommends that itinerant West African migrant traders should invest more of their resources in the sale of electronics and accessories as it has the highest potential of guaranteeing secured and improved livelihoods. Any form of business support aim at improving the livelihood status of itinerant immigrant traders should be focused on young and female itinerant traders and those engaged in the sale of food-related items because they were less likely to maintain improved livelihood status.
\end{abstract}

Keywords: Accra metropolitan area, Livelihood activity, West African migrants

\section{Introduction}

In spite of advances in modern retailing, a greater number of people throughout the world still earn their livelihood partly or exclusively through itinerant trading of goods on the streets (Skinner, 2008; Ghana Statistical Service [GSS], 2012; Koroma et al., 2017). In stressing this view, Little (1999) and Turner and Oswin (2015) stated that itinerant trading of wares is a common livelihood activity, particularly in the global south and that it is widely undertaken in urban settings with a significant customer base. The term itinerant trade is defined as a livelihood activity that takes place outside the shop environment or formal norms of economic transactions established by the state and formal business practice (American Association of Pharmaceutical Scientists [AAPS], n.d.; Hart, 1973; Skinner, 2008;

(c) The Author(s). 2019 Open Access This article is distributed under the terms of the Creative Commons Attribution 4.0 International License (http://creativecommons.org/licenses/by/4.0/), which permits unrestricted use, distribution, and reproduction in any medium, provided you give appropriate credit to the original author(s) and the source, provide a link to the Creative Commons license, and indicate if changes were made. 
Ghana Statistical Service [GSS], 2012). This covers costermongers selling food products on the streets of major cities; hawkers and peddlers with trays or barrows of wares selling along the streets or selling door to door (Thorsen, 2012). In this study, itinerant traders have been conceptualized as mobile retailers who sell wares using different instruments to aid mobility (e.g. bicycles, hand cart, trolley-pushers, barrows) or who moved from one place to another by foot.

According to Skinner (2008) and Peberdy (2016), a major factor that swells the number of itinerant street traders in sub-Saharan Africa is international migration. As Landau (2007) points out, international migration is an inexorable response to regional economic inequalities. Itinerant trading is thus what many foreign immigrants opt to do at their destinations. Lonreco-Lindell (2004) for example cites the case of the Dyulas-itinerant traders who have been active in West Africa for centuries, moving goods across borders. For many villages, itinerant migrant traders are the primary source of supplies (Skinner, 2008). Peberdy's (2016) study, one of the few surveys on cross border traders in Southern Africa, suggested that itinerant migrant traders either supply domestic street traders or sell their wares directly.

Adepoju (2005), Olsen (2011) and International Organization for Migration [IOM] (2013) observed that migrants in West Africa have historically considered the sub-region as one big economic unit within which trade in goods and services typically flow, and that itinerant trade had been an important feature of the phenomenon. Rouch (1956), one of the pioneers who highlighted the significance of itinerant migrant trading in the twentieth-century West Africa, noted that most of the immigrants to Ghana were self-employed itinerant retailers from Nigeria, Burkina Faso, Mali, Niger and Togo rather than wage labourers. The pervasiveness of itinerant trading of migrants has also been corroborated by Peil (1974), Eades (1994), Anarfi et al. (1997), Aniegye (2012) and GSS (2014), who indicated that itinerant migrant traders have played significant roles in the economy of Ghana by guaranteeing access to essential commodities and services. GSS (2013) and Ajavon (2014) argued that the recent increases in informal trading activities in Ghana is largely attributed to the influx of undocumented immigrants from neighbouring West African countries and immigrant entrepreneurs from outside the African continent namely Lebanon and China.

While acknowledging that a number of studies have documented the presence and trading activities of immigrants in Ghana (Akyeampong, 2006; Debrah, 2007; Obeng, 2015; Antwi-Bosiakoh, 2009; Aniegye, 2012; Ajavon, 2014; Fadayomi et al., 2014; Ohene-Marfo, 2014), studies concerning the characteristics and livelihood activities of itinerant West African migrant traders have not attracted much research attention in contemporary times (Ghana Statistical Service [GSS], 2012; GSS, 2013; Bello-Bravo, 2015; Antwi-Bosiakoh 2016). Meanwhile, Ghana as one of the main economic hubs of West Africa hosts a significant number of these immigrants who predominantly subsist in itinerant petty trading across the country (Bakewell \& Jónsson, 2011; GSS 2013). Many of these itinerant immigrant traders have become somewhat integrated into the country and have taken advantage of the Economic Community of West African States [ECOWAS] protocol on free movement and establishment to create their own itinerant retail businesses and commutes between Ghana and their home countries (Awumbila et al., 2009; Aniegye, 2012; GSS, 2013). Based on the above gap in research, the study advances the following research questions: who are these itinerant immigrant traders? 
What specific livelihood activities do they undertake? And has their livelihood status improved or otherwise?

According to Cerase (1974), Gmelch (1980), Tanle (2010), Yendaw (2013) and the United Nations [UN] (2017), the livelihood status of migrants can be measured by assessing their social and economic conditions in terms of employment and housing, social status (such as social networks), access to basic necessities of life (e.g. food, health care), income earnings and savings, and ownership of consumer durable goods and other capital assets. Similarly, the migrants' own perceptions could also be measured based on their degree of satisfaction or dissatisfaction with their migration experiences. With this background, this study assesses the livelihood status of the immigrant traders in the Accra Metropolis. Assessing the livelihood status of migrants is important because improvement or deterioration of their livelihood status at destination has serious policy implications for both places of origin and destination. The paper is divided into six main sections: introduction, theoretical and conceptual perspectives, study context, data and methods, results and discussions and conclusions and implications.

\section{Theoretical and conceptual perspectives}

The term 'livelihood' is derived from the 'sustainable livelihood' approach which has been generally defined as a means of living, which is resilient to shocks and stresses, and also does not adversely affect the environment (McDowell \& de Haan, 1997; De Haas, 2006; Petersen \& Pedersen, 2010; Rigg et al., 2014). Drawing on the works of Chambers and Conway (1992) and Carney (1998), livelihood is defined as the capabilities and assets (including both material and social resources) that an individual possesses and the activities he/she undertakes to earn a living. A livelihood strategy can then be defined as a strategic or deliberate choice of a combination of activities by households and their individual members to maintain and improve their livelihood (Department for International Development [DFID], 1999; Tanle, 2010, 2014). This choice of livelihood activities is often based on access to assets, perceptions of opportunities, as well as aspirations of actors involved (Meikle, 2001; Waddington, 2003; Moreda, 2012).

Understanding people's livelihoods particularly migrants (whether sustainable or not), has become an important focus within the international development literature and policy debates (Meikle, 2001; United Nations Development Programme [UNDP], 2009; Songsore, 2011; UN, 2017). However, Cahn (2002), Duffield (2010) and Tanle (2015) have lamented that the relationship between migration and livelihood has not been sufficiently established. This makes the connections between migration and livelihood indistinct (Tanle, 2010). Migration has been recognized as one of the many strategies households and individuals employ to diversify their livelihoods (Hunters \& Skinner, 2001; Awumbila, 2017). This according to Bebbington (1999), Ellis (2000) and Daskon and Binns (2009) is often combined with other livelihood strategies such as agricultural intensification and local non-farm activities. Tanle (2010) and Rigg et al. (2014) observed that migration is often more than just a short-term survival strategy by rural populations, who are uprooted by global capitalist forces and more or less forced to join the ranks of a new international proletariat. Rather, it is a deliberate decision to improve livelihoods, enable investments and help to reduce fluctuations in the family income (De Haas, 2009b; Awumbila, 2017). 
Migration is seen as a means to acquire a wider range of assets which insure households and individuals against future shocks and stresses (McDowell \& de Haan, 1997; de Haan et al., 2000; De Haas, 2009a, b; World Bank, 2017). In supporting this claim, a study by Chowdhury et al. (2012) and Rigg et al. (2014) revealed how migration positively contributed to the development of poor people where their social and economic conditions such as household income and savings, land possession, expenditure, non-productive assets, housing status and social participation among others improved in comparison to the same factors before migration. Although this 'diversification-through-migration' argument has been mainly applied to rural-urban internal migration in poor countries, it could be applied to international migration, in particular, the migration of some West African immigrants who reside and work in Ghana as itinerant petty traders.

The framework for migration and livelihood studies developed by Tanle (2015) was adapted to provide conceptual guidance for this study which sought to assess the livelihood status of itinerant West African immigrant traders in the Accra Metropolis. Its main advantage over other livelihood frameworks (e.g. DFID and the Pacific Islands' SL frameworks) is that it has direct links to issues of migration and livelihoods and has included in its analysis the personal characteristics of migrants and background characteristics of both places of origin and destination. These personal and background characteristics in the view of Tanle (2015) are critical components in migration and livelihood analysis particularly on issues relating to the types of livelihood strategies migrants can undertake and the outcomes of their livelihood strategies (Fig. 1).

The conceptual framework for the study comprises three main elements: background characteristics, livelihood strategy and livelihood outcome or status. Background characteristics in the study consist of six components namely personal characteristics of the immigrants (e.g. country of origin, sex, age, education, duration in business etc.), socio-cultural factors (e.g. gender power relations, access to essential facilities/services), economic factors (e.g. income generating opportunities), political factors (e.g. insecurity), historical factors (e.g. shared colonial and migration experiences) and environmental factors (e.g. physical characteristics). The personal and background characteristics influence the desire to migrate, the livelihood strategy or activity to undertake, the level of vulnerability and livelihood outcomes (status) at both the origin and destination as well as the

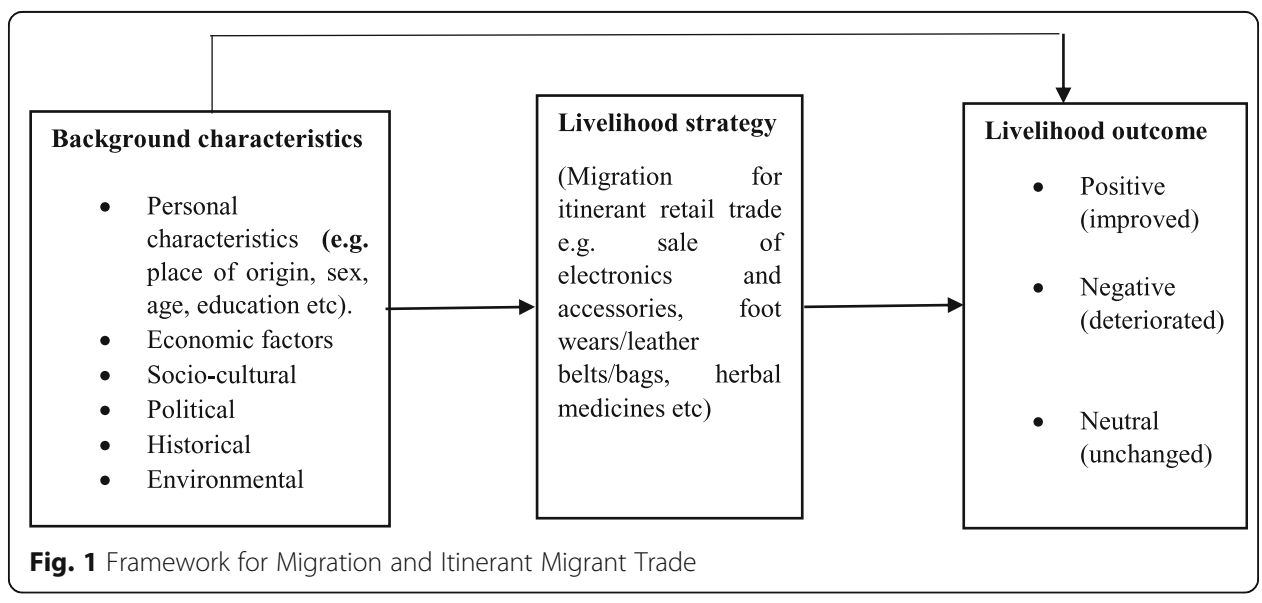


institutional structures and processes that surround their livelihood activities. For example, the immigrants' livelihood status (as to whether it has improved or deteriorated) is likely to be impacted positively or negatively by their personal characteristics (e.g. sex, education, household size, type of trading activity, duration in trade among others) and the socio-economic circumstances of their areas of origin and destination.

In the framework, livelihood strategy consists of various livelihood activities undertaken by individuals and households to make a living. In this study, the main livelihood strategy adopted among the immigrants is migration for itinerant retail trade. According to the framework for migration and livelihood studies (Tanle, 2015), the types of livelihood strategies migrants undertake are a function of their background characteristics (e.g. sex, age, education, place of origin). In line with this view, Tanle (2014) and Awumbila (2017) maintained that migrants tend to engage in livelihood activities which in their view afford them the greatest or optimal livelihood status (measured by their earnings and savings, access to essential goods and services and general socio-economic wellbeing). Based on the above observations in the conceptual framework (Fig. 1), it was hypothesised in the study that the socio-demographic characteristics of the immigrant traders and the types of trading activities they undertake at the destination had significant influence on their livelihood status (i.e. whether it has improved or deteriorated).

The ultimate component of the conceptual framework is livelihood outcome which is a function of the types of livelihood activities the immigrants undertake and their personal characteristics (Fig. 1). Theoretically, a livelihood can either be positive [improve], negative [deteriorate] or neutral [remain the same] (GSS, 2013; Tanle, 2010, 2015). Positive outcomes denote improved livelihood status measured by improved food security, security of employment, increased incomes, improved human and social capitals, and increased assets (including access to land or land ownership and other consumer durable goods), reduction in vulnerability, and ultimately improvement in general wellbeing (Rigg et al., 2014). Negative livelihood outcome according to UNDP (2009) is denoted by increased vulnerability, and decline in livelihood status and well-being. Neutral outcomes on the other hand signify neither positive nor negative changes in the lives of the immigrants. Nevertheless, the livelihood status of the immigrants in this study was subjectively measured as either positive or negative due to the fact that the livelihood status of people cannot remain unchanged.

\section{Study context}

The study was carried out in the Accra Metropolitan Area [AMA], the regional capital of the Greater Accra Region and the administrative capital of the Republic of Ghana (Ghana Statistical Service [GSS], 2012). This is because the 2010 Population and Housing Census [PHC] reports revealed that over $21.0 \%$ of ECOWAS nationals dwelled in the Greater Accra region [which is the highest compared to other regions in Ghana] and AMA hosted the largest proportion of these immigrants (GSS, 2013, 2014). The AMA is one of the 216 Metropolitan, Municipal and District Assemblies [MMDAs] in Ghana and also among the 16 MMDAs in the Greater Accra Region (GSS, 2014). According to the 2010 PHC reports, the population of AMA stood at 1,665,086 representing $42.0 \%$ of the region's total population (GSS, 2014). Males constitute. 
48.1\% and females represent $51.9 \%$. The AMA (Fig. 2) is entirely urban and the age structure of the area shows a youthful population which is typical of most developing countries. The age distribution shows that people in the age group of 20-24 years form the highest proportion followed by those in the age cohort of 25-29 years (Ghana Statistical Service [GSS], 2012). The current age structure according to GSS $(2013,2014)$ is attributed to the influx of both internal and international migrants into the Metropolis for various purposes including trading.

The 2010 PHC revealed that of the total population of 1,665,086 inhabitants in the AMA, about $47.0 \%(778,267)$ are migrants (born elsewhere in the Greater Accra Region or other regions in Ghana or outside Ghana). The 2010 PHC figures also showed that of the total migrant population in the Metropolis $(778,267)$, about 409,910 are immigrants from within the ECOWAS representing about $53.0 \%$ of the total migrant populations (GSS, 2014). There are more male ECOWAS nationals $(1.6 \%)$ than females (1.3\%) (GSS, 2013). In terms of duration of residence in the AMA, the highest proportion of migrants outside Ghana (36.2\%) reside in the Metropolis between 1 and 4 years (GSS, 2014). As regards the main economic activities of the AMA, the 2010 PHC reports indicate that the majority of residents are engaged in commerce and service related occupations (Ghana Statistical Service [GSS], 2012, 2014). The AMA (Fig. 2) hosts a large number of manufacturing industries, oil companies, financial institutions, telecommunication, tourism, education, health institutions and other important establishments. The presence of these infrastructure and opportunities continue to attract both indigenes and foreigners to transact various businesses (GSS, 2013).

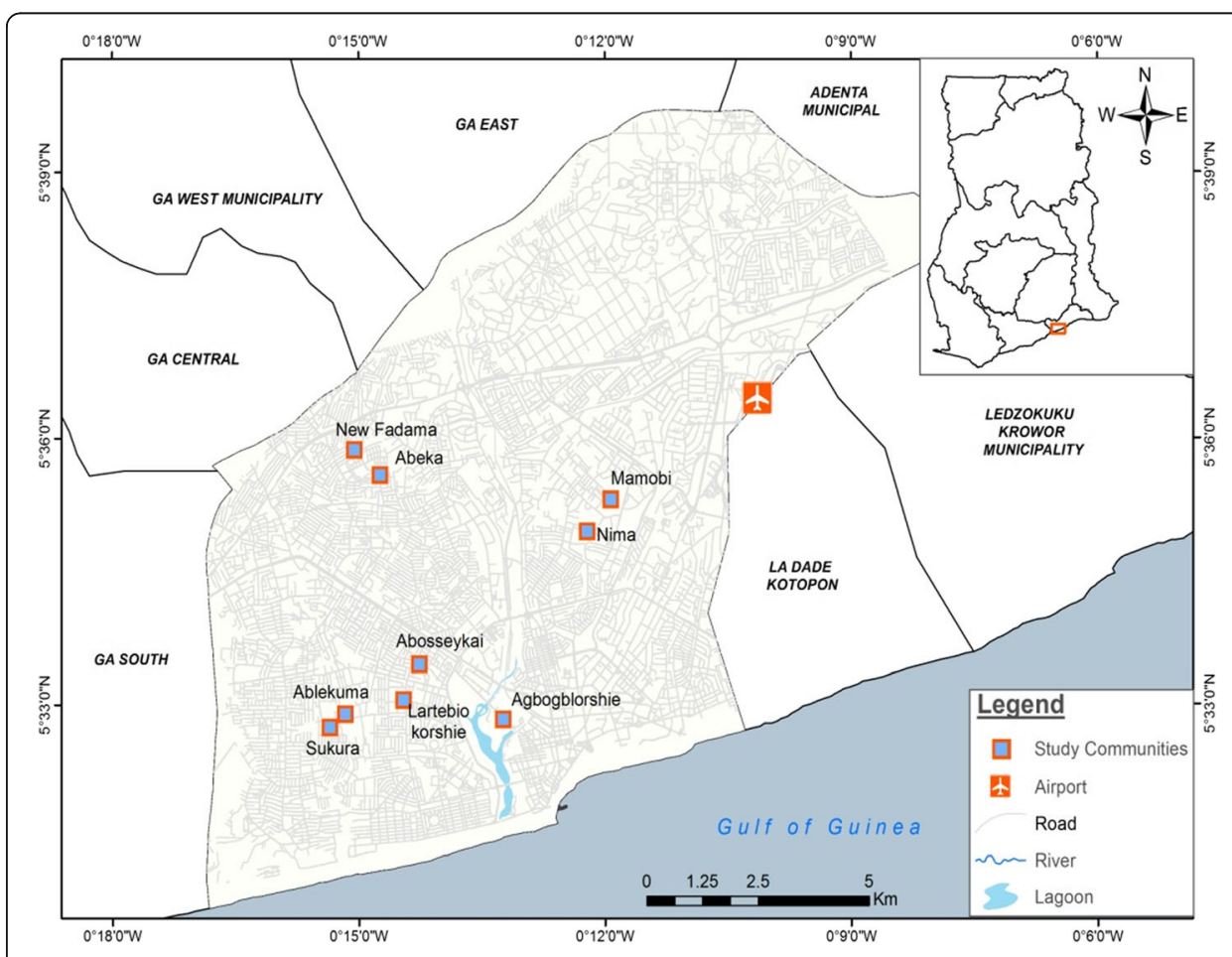

Fig. 2 Map of Accra Metropolis Showing the Study Sites. Source: GIS Unit of the Department of Geography and Regional Planning (2017) 


\section{Data and methods}

The study was cross-sectional in nature and used the quantitative dominant concurrent nested (QUANT+qual) design for this study. Accordingly, in terms of status and integration, the study was largely quantitative dominant both at the data collection and the analysis stages with the qualitative dimension playing a supportive role. Data for the study were mainly derived from a survey and in-depth interviews from a much wider study conducted in 2017 in the Accra Metropolis. The data covered the socio-demographic characteristics of the immigrants, their main trading activities, and issues on their overall livelihood status. The target population comprised West African migrants who were engaged in any form of itinerant petty trading in the AMA. The inclusion and exclusion criteria for the study involved two issues 1) the immigrant must have engaged in itinerant trading for at least one year and 2) must not be a dual national, naturalized or a national by marriage. The one-year benchmark was adopted in selecting the immigrants because the UN classifies people who reside in countries of destinations for 1 year or more as permanent migrants and describes those who stay below 1 year as temporary migrants or visitors. The $2010 \mathrm{PHC}$ reports also reveal that the longest duration of stay of most foreign migrants in the AMA is between 1 and 4 years (GSS, 2014). The unit of analysis was the individual itinerant immigrant trader and the data obtained from the field were analysed at the individual immigrant level.

Due to the urbanized and congested nature of the AMA, nine communities with the highest concentration of itinerant traders were purposively sampled for the study. These communities were Abeka, Ablekuma, Abossey Okai, Agbogbloshie, New Fadama, Lartebiokorshie, Sukura, Nima and Mamobi. (Antwi-Bosiakoh, 2009; GSS 2014; Serbeh et al., 2015). The snowballing technique was employed to generate a sample frame of 842 itinerant traders in the nine communities. The sample frame of 842 itinerant traders was used as the sample size because quantitative approaches demand large sample sizes for rigorous statistical analysis (Fawcett \& Arnold, 1987). One major flaw, however, for using the snowball technique was that sampling bias could not be ruled out.

As regards the qualitative dimension of the study, 12 key informants who had in-depth knowledge about the immigrants' trading activities were purposively selected and interviewed. These comprised one interviewee each of Ghana Immigration Service [GIS], Ghana Union of Traders Association [GUTA], and Ghana Investment Promotion Centre $[$ GIPC]. The other interviewees were nine leaders of the immigrant traders (one from each study community) who were responsible for the coordination of their itinerant trading activities in the study sites. Interview schedule (researcher-administered questionnaire) and in-depth interview guide [IDI] were used to collect the data for the study. The interview schedule helped because the questions were worded in the English Language as most West African immigrants in itinerant petty trading in Ghana are either illiterates or not well educated enough to read and understand the English Language (GSS, 2013), particularly those who originated from Francophone countries. The instruments were administered by the researcher and four trained field assistants in the local languages (Asante Twi and Ga), English, French and Hausa which are the dominant languages spoken among the immigrant traders. The instrument comprised both open-ended and closed ended questions.

The interview schedule and the IDI guide were structured in three main parts. The first part elicited responses on the socio-demographic characteristics of the 
immigrants (e.g. sex, country of origin, age, education, marital status, duration in trade, previous occupation at origin, religious affiliation \& household size) while the second part covered their main itinerant trading activities at the destination. The last aspect of the instruments assessed their livelihood status using seven main livelihood indicators namely: permanency of their occupation [improved job security], ability to afford adequate food for themselves and their families [improved food security], ability to afford their health care needs, ability to withstand occasional price shocks on basic necessities of life [improved vulnerability], acquisition of household assets and formation of relevant social capital to depend on during difficult times (improved social networks).

The instruments were pre-tested in the Kumasi Metropolis to evaluate their face and content validity. The actual data collection began on January 20th 2017 through to 20th March 2017. All protocols involving community entry were conscientiously observed with opinion leaders (assembly members and the immigrant leaders) who then served as focal persons throughout the study and helped the research team contact the selected respondents for the survey. Data from the interview schedule and interview guide were first cross-checked to ensure they were completed and accurate. Afterwards, it was noticed that out of the 842 interview schedule administered, 779 of them were found suitable for processing and analysis representing a response rate of $92.5 \%$. The interview schedule was then numbered serially and keyed into SPSS (version 21) for further processing and analysis. The Cronbach's Alpha value was calculated to ascertain the data quality/reliability prior to the analysis. Descriptive and inferential statistical tools were used to analyse and present the data. As regards the descriptive analyses, frequency distributions, percentages, cross-tabulations were the main method of data reporting. Further, binary logistic regression model was used to test the hypotheses stated because the dependent variables were categorical. The rationale was to test models to predict categorical outcomes with two or more categories. Data from the IDI guides were transcribed verbatim and manually analysed. The direct quotations from the patterns that emerged from the analysis was adopted in the presentation of the findings. The 'member check' approach was used to validate the results from the in-depth interviews. Ethical clearance with protocol identification number (UCCIRB/CHLS/2016/23) was obtained from the Institutional Review Board of the University of Cape Coast before the study commenced.

\section{Results and discussion}

\section{Socio-demographic characteristics}

Table 1 presents the socio-demographic characteristics of the immigrant traders captured in the survey. The results indicate that a higher proportion of the immigrants were itinerant traders from Niger $(42.2 \%)$ and Mali $(22.6 \%)$ which underpin the observation made by IOM (2015) and Yaro (2008) that intra-regional mobility in West Africa is generally dominated by North-South movement from landlocked countries of Sahel West Africa such as Niger and Mali to the more prosperous cities of coastal West Africa predominantly Côte d'Ivoire, Ghana, and Nigeria. With respect to sex composition of the immigrants, the results showed that about nine out of ten were males. In 
terms of age distribution, over six out of ten (61.5\%) were aged between 20 and 29 years while a few $(7.1 \%)$ were in the age category of $40-49$ years. Table 1 further suggests that nearly $60.0 \%$ were never married (single) and over a sixth.

(66.7\%) of them were without formal education. The analysis also indicates that the majority (97.0\%) of the immigrant traders were Muslims and about half of them had household sizes of one to four members. These revelations from the study confirm what Konseiga (2005), Olsen (2011) and ECOWAS Commission (2014) had observed that the main feature of migratory movements in West Africa is male-dominated who are more likely to be young and unmarried.

The current findings (Table 1) also support what Stenou (2004), Adepoju (2005) and GSS (2013) indicated that most migrants within the region generally lack basic skills to compete for formal sector jobs at the new destination. The youthful age composition of the immigrant traders (Table 1) suggests that they are capable of improving upon their human capital and ultimately their livelihood status. Table 1 further revealed that about $65.0 \%$ of the immigrants were farmers prior to migration and more than two-thirds $(81.3 \%)$ were engaged in their current trading activities for 1-4 years which lends credence to what has been stated by GSS (2013, 2014) that most West African immigrants in Ghana are predominantly rural farmers prior to migration and that the majority of them dwell in the Accra Metropolis for between 1 and 4 years.

\section{Type of trading activities}

Table 2 shows that the immigrants were largely engaged in the sale of leather belts/foot wears/bags (18.0\%) and traditional herbal medicines (17.0\%) while itinerant vending of food products $(7.3 \%)$ emerged as the least trading activity. Evidence from qualitative interviews with leaders of the immigrant traders added further context to the quantitative findings. During the interviews, one interviewee from Niger chronicled the types of products mostly retailed among them. He indicated that most itinerant traders from West Africa do not usually sell one item and that the types of goods sold among the immigrants generally vary from time to time and that it depended on what was trending in the market area at any given period. The excerpt below presents the types of wares he was involved in at the time of the interview:

The items I sell vary from time to time depending on how the market is moving. Sometimes I roam with shoes, bags, lamps and perfumes. Another time I go into clothing. For example, these electronics gadgets I am selling right now last year I was not selling them, I was selling DVDs/CDs recorder/players and mobile phone accessories you see [45-year old interviewee from Niger].

A contrary view regarding the immigrants' trading activities was, however, held by an interviewee from GIPC (the institution that coordinates the trading activities of foreigners in Ghana). During the interview, this was what was said about their main trading activities:

Most of itinerant West African immigrants in the Accra Metropolis are generally engaged in the retail of textiles, electrical appliances and books [59-year old interviewee from GIPC]. 
Table 1 Socio-demographic characteristics

\begin{tabular}{|c|c|c|}
\hline Socio-demographic characteristics & Number & Percent \\
\hline \multicolumn{3}{|l|}{ Country of origin } \\
\hline Benin & 39 & 5.0 \\
\hline Burkina Faso & 32 & 4.1 \\
\hline Mali & 176 & 22.6 \\
\hline Niger & 329 & 42.2 \\
\hline Nigeria & 146 & 18.7 \\
\hline Togo & 49 & 6.3 \\
\hline Other & 8 & 1.1 \\
\hline \multicolumn{3}{|l|}{ Sex } \\
\hline Male & 694 & 89.1 \\
\hline Female & 85 & 10.9 \\
\hline \multicolumn{3}{|l|}{ Age in completed years } \\
\hline$<20$ & 89 & 11.4 \\
\hline $20-29$ & 479 & 61.5 \\
\hline $30-39$ & 164 & 20.0 \\
\hline $40-49$ & 55 & 7.1 \\
\hline \multicolumn{3}{|l|}{ Marital status } \\
\hline Never married & 462 & 59.3 \\
\hline Married & 294 & 37.7 \\
\hline Widowed & 13 & 1.7 \\
\hline Divorced/Separated & 10 & 1.3 \\
\hline \multicolumn{3}{|l|}{ Educational attainment } \\
\hline No formal education & 520 & 66.7 \\
\hline Basic education & 188 & 31.1 \\
\hline Secondary/tertiary & 16 & 2.2 \\
\hline \multicolumn{3}{|l|}{ Religious affiliation } \\
\hline Christianity & 23 & 3.0 \\
\hline Islam & 756 & 97.0 \\
\hline \multicolumn{3}{|l|}{ Household size } \\
\hline $1-4$ & 335 & 42.5 \\
\hline $5-8$ & 250 & 32.1 \\
\hline$>8$ & 194 & 24.9 \\
\hline \multicolumn{3}{|l|}{ Occupation before migration } \\
\hline Artisan & 9 & 1.2 \\
\hline Trading & 150 & 19.3 \\
\hline Services & 50 & 6.4 \\
\hline Farming & 505 & 64.8 \\
\hline Unemployed & 58 & 7.4 \\
\hline Other & 7 & 0.9 \\
\hline \multicolumn{3}{|l|}{ Duration in trade (in years) } \\
\hline $1-4$ & 633 & 81.3 \\
\hline $5-8$ & 129 & 16.6 \\
\hline$\geq 9$ & 17 & 2.1 \\
\hline
\end{tabular}

Source: Field survey, 2017 


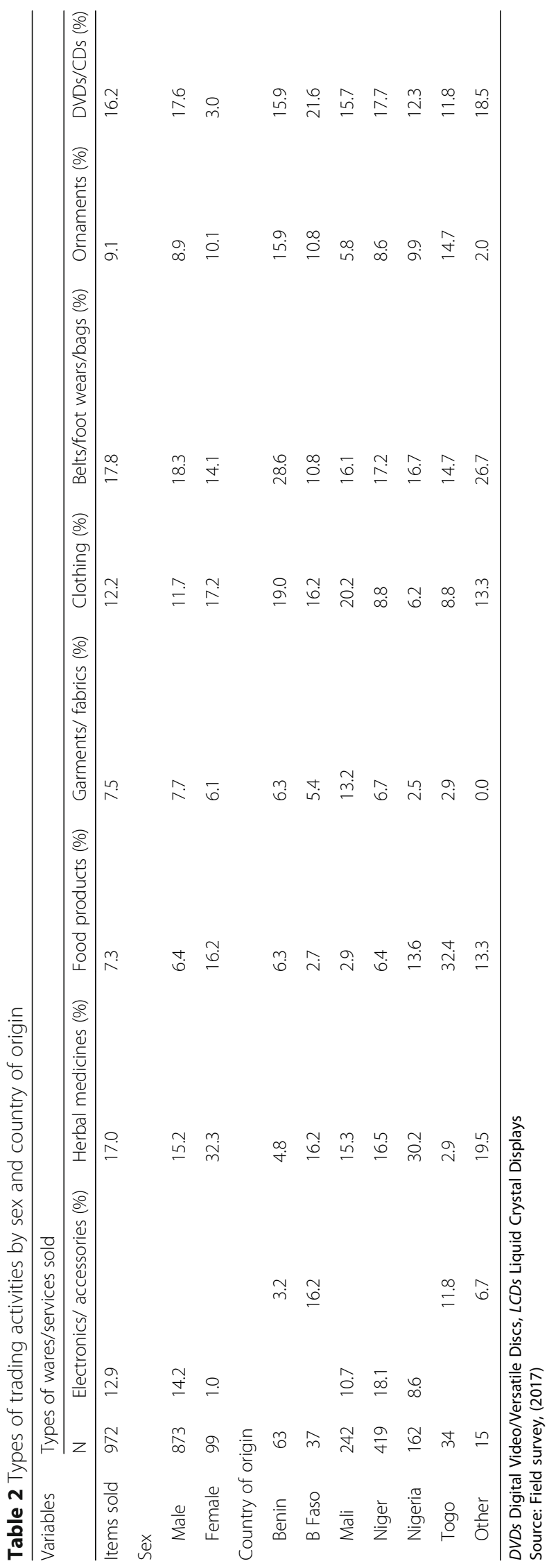


Given that most of the immigrants were engaged in the sale of foot wears/leather belts/ bags $(17.8 \%)$ and traditional herbal medicines (17.0\%) contradict similar findings by Hunters and Skinner (2001) among itinerant foreign retailers in Durban South Africa where nearly about half of their study sample (47.0\%) was involved in the provision of haircut and shoe shining or repair services.

Although men and women across the various countries of origin were involved in the sale of all the wares outlined in Table 2, there appears to be gender and country specific differences in the types of wares sold. In the study, whereas men were generally engaged in the retail of foot wears/leather belts/bags, DVDs/LCDs players/recorders and electronics/accessories, their women counterparts dealt in a broader range of wares namely: herbal medicines, food items, clothes and valuable ornaments (Table 2). This finding as shown in Table 2 was anticipated because trading activities involving the retail of foot wears/leather belts/bags, electronics/accessories and DVDs/LCDs players/recorders are generally perceived as masculine related occupations in most societies in West Africa (Aniegye, 2012; Gough \& Langevang, 2016). The current evidence presented in Table 2 also confirms findings by Hunters and Skinner (2001) and Awumbila et al. (2009) where the type of goods traded among transnational migrant traders were diverse across gender.

Similar patterns in the immigrants' trading activities were observed across their countries of origin with some nationals specialising in specific business activities (Table 2). For instance, while immigrants from Benin (28.6\%) were largely specialised in the sale of foot wears/leader belts/bags, their counterparts from Nigeria (30.2\%) were generally engaged in the sale of traditional herbal medicines (Table 2). These differences in the type of wares sold across countries and sex (Table 2) go to support the observations made in the conceptual framework for the study (Fig. 1) that immigrants' personal characteristics such as sex and country of origin have the proclivity to influence their livelihood activities at their destinations. One major observation made from both the quantitative and qualitative studies was that the types of wares sold among the immigrants were at variance with wares which were hitherto transacted among commercial migrant traders in the pre-colonial and colonial epochs (Akinjogbin, 1980). For instance, Peil (1974) and Aniegye (2012) recounted that the trading activities of commercial migrants in West Africa during the pre-colonial and colonial era were centred on commodities like kola-nuts, salt, cloths, gold, ivory, and tobacco among others. These differences could be largely attributed to the pervasiveness of foreign manufactured merchandise from the Asian markets (e.g. China) and the proliferation of modern manufacturing industries across the West Africa sub-region (Debrah, 2007; GSS, 2013; Ajavon, 2014).

\section{Livelihood status}

Seven different binary logistic regression models were used to estimate the livelihood status of the immigrant retailers (Table 3). The focus of the analysis was to ascertain whether their socio-demographic characteristics (sex, age, country of origin, main trading activity and duration in trade) had any influence on their livelihood status. In each of the models, improved livelihood status was designated as one representing increasing odds in favour of positive livelihood status while deteriorated livelihood status was 


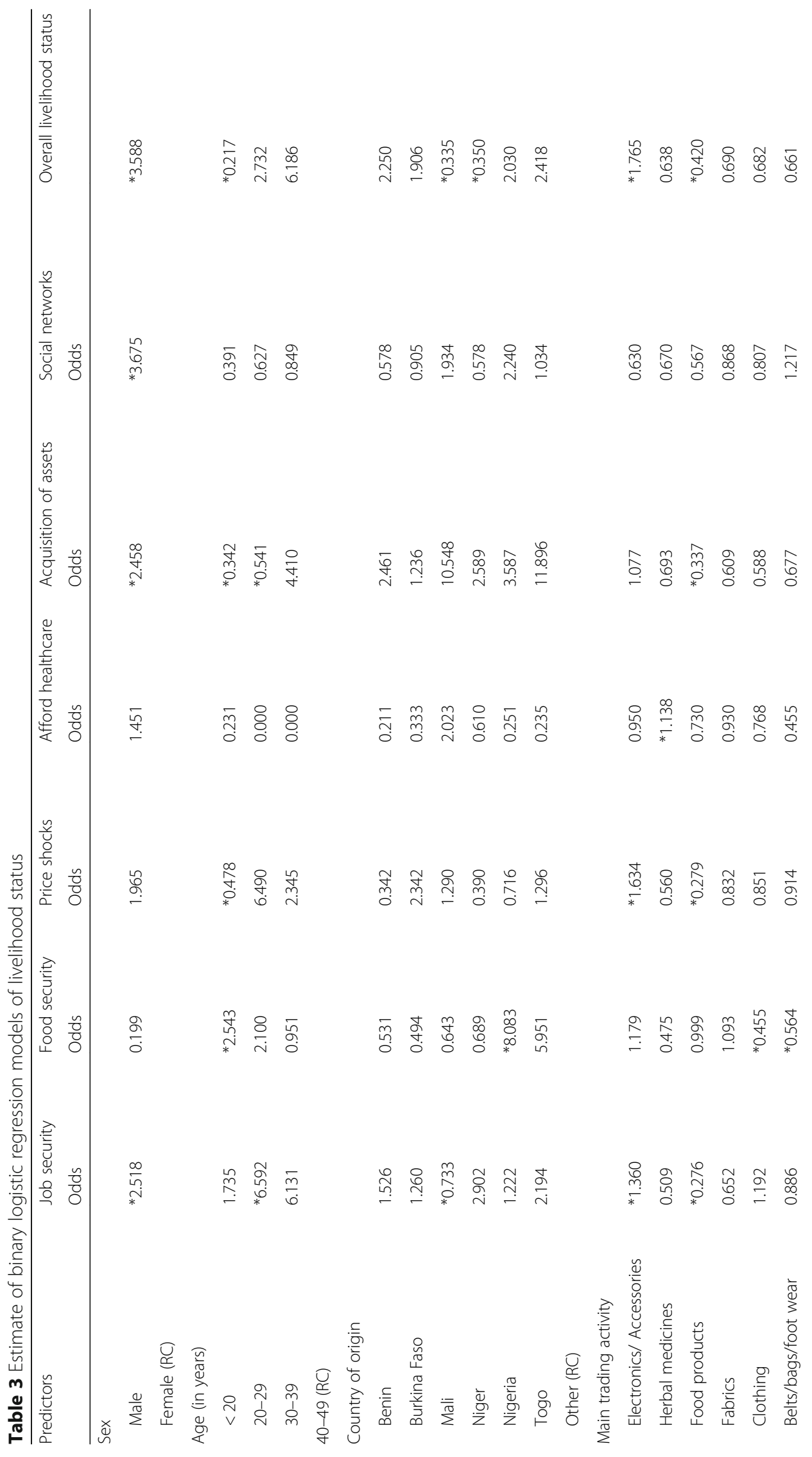




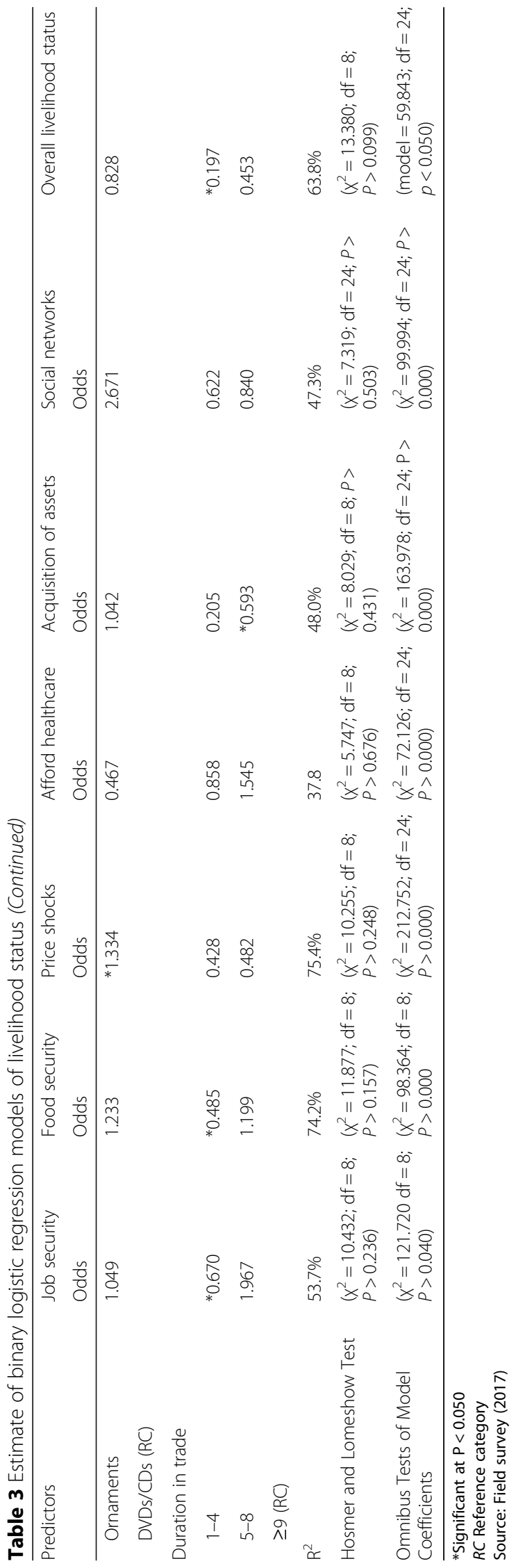


captured as zero signifying decreasing odds in favour of negative livelihood status. The analyses (Table 3) showed that all the five independent variables demonstrated to be good predictors of the various indicators of their livelihood status. According to Pallant (2005), a model is considered as a good predictor, when the alpha value of the Hosmer and Lemeshow Test is greater than 0.05 and in the case of the output of these data (Table 3), all the alpha values were greater than 0.05 , and thus signified a strong reliability of the models.

Results from the binary logistic regression models (Table 3) showed that background characteristics of the immigrant traders (sex, age, country of origin, duration in business, type of wares traded) were significant predictors of their livelihood status which accentuate the basic assumptions of the conceptual framework for the study (framework for migration and itinerant migrant trade) and the framework for migration and livelihood studies by Tanle (2015) that personal characteristics of migrants have significant influence on the livelihood outcome of their trading activities such as their income earnings and general livelihood status. The current revelations as typified in Table 3 similarly corroborate earlier studies by Waddington (2003), International Labour Organization [ILO] (2002) and Rigg et al. (2014) that the socio-demographic characteristics of migrants have the tendency to affect their livelihood strategies and overall livelihood status. Specifically, male itinerant traders were about three times more likely to have improved job security as compared to their female counterparts due to their migration (Table 3). This finding as shown in Table 3 supports the observation made by Ghana Statistical Service [GSS], (2012) that female entrepreneurs are generally vulnerable in the market environment and thus most likely to have insecure livelihoods due to excessive and unfair competition from their male counterparts.

With respect to acquisition of household assets (Table 3), it was again found that males were about 2.458 times more likely to accumulate sufficient assets as compared to their female compatriots. This was anticipated because in many social settings in Africa, males are generally regarded as the breadwinners and material providers of their families or households and are, therefore, mandated to provide the needed household assets and facilities for the comfort of their household members (Anarfi et al., 2003; Tanle, 2010; GSS, 2013). Also, male immigrants were about four times more likely to have sufficient social networks to depend on during difficult moments as compared to the reference category (Table 3) which was expected because females by the nature of their upbringing are taught to be mindful in relating with people in society, especially the opposite sex. Moreover, the cultural and conjugal obligations imposed on females particularly those who are married are such that they are usually not expected to mingle freely with others as men do or depend on others especially the opposite sex for any form of assistance except their spouses. This for sure might have affected their social connections. In terms of the overall livelihood status of the immigrant traders, it was found that males were about four times more likely to better their lots as compared to their female folks (Table 3).

Again, age had significant impact on the livelihood status of the immigrant traders (Table 3). Immigrants who were aged between 20 and 29 years were about seven times more likely to have improved job security as compared to those who 
were older ( $40-49$ years). This finding was not surprising because given the strenuous nature of itinerant trading (which largely involves moving from one location to the other), it is only natural that migrants who are youthful are more likely to be energetic and agile enough to undertake this form of business transactions with ease and make sufficient profits to guarantee the security of their businesses. As indicated by the human capital model proposed by Sjaastad (1962), Tanle (2010) and Ghana Statistical Service [GSS] (2012), the quality of human capital of a migrant would, to a greater extent, influence his/her livelihood status. The study as well revealed that immigrant traders who were younger $(<20$ years $)$ were about three times more likely to achieve improved food security as compared to those who were older (40-49 years). This could be based on the fact that migrants who are relatively younger are more likely to be unmarried and thus has no responsibility of providing the food needs of their households or families.

Contrarily, it was noticed that immigrant traders who were less than 20 years were about 0.478 times less likely to reduce vulnerabilities to occasional price shocks on basic necessities as compared to those who were older (40-49 years) (Table 3). The current finding could be attributed to the fact that these group of immigrants (those aged $<20)$ might have been inexperienced in the business as compared to those who were older to overcome occasional prices shocks. As regards assets acquisition, Table 3 revealed that immigrants who were young $(<20-29$ years) were less likely to have improved asset-holding status as compared to those who were older (40-49 years). This revelation again could be due to the fact that those immigrant traders who were elderly might have been involved in their itinerant trading activities for longer periods and are, therefore, more likely to accumulate sufficient assets. In general, age indicated a statistically significant effect on the overall livelihood status of the immigrant traders and those who were much younger $(<20$ years) were less likely to better their lots as compared to those who were older (40-45 years) (Table 3$)$.

In addition, country of origin indicated a statistically significant effect on the livelihood status of the immigrant traders (Table 3). While immigrant retailers from Mali were about 0.733 less likely to have improved job security, it was found that immigrants who originated from Togo were about twelve times more likely to achieve improved job security as compared to the reference category. The analysis (Table 3) further showed that whereas Burkinabes were 0.494 times less likely to achieve improved food security as compared to those from other countries, it was discovered that immigrants who were of Nigerian origin were eight times more likely to have improved food security. In general, the immigrants' countries of origin were significantly associated with their general livelihood status and immigrants from Mali (0.335) and those from Niger (0.350) were less likely to achieve improvement in their overall livelihood status (Table 3) which authenticates what has been observed in the conceptual framework for the study (Fig. 1) that socio-economic disparities between migrants' areas of origin has the proclivity to impact positively or negatively on their livelihood status.

A statistically significant relationship was also found between types of wares sold among the immigrants and their livelihood status (Table 3). For instance, while itinerant traders of electronics and accessories were 1.360 times more likely to have improved job security, those engaged in the sale of food-related items were 0.276 times less likely to attain improved job security (Table 3). Equally, immigrants who were 
involved in the retail of foot wears/leather belts/bags (0.564) and clothing (0.455) were less likely to better their lots in the area of food security as compared to the reference category (Table 3). With respect to vulnerabilities to occasional price shocks (Table 3), it was again found that itinerant retailers of electronics and accessories were about two times more likely to reduce vulnerabilities to occasional price shocks on basic necessities which confirms the claim by Roever and Linares (2008) that sellers of durable products like electronics and accessories are less exposed to asset loss and price fluctuations compared to other types of goods traded. In general, itinerant traders of garments/fabrics $(0.279)$ had the least likelihood of reducing vulnerabilities to occasional price shocks as compared to the reference category.

With regard to access to healthcare services (Table 3), it was found that itinerant traders of traditional herbal medicines were 1.138 times more likely to have improved healthcare access as compared to reference category which could be explained by their involvement in the sale of various traditional herbal medicines which perhaps may have made them believe that they have the wherewithal to afford their healthcare needs. As regards the acquisition of household assets, the analysis indicated that itinerant traders of food items (0.337) were less likely to have improved asset-holding status as compared to the reference category (Table 3). An assessment of the overall livelihood status of the immigrant traders revealed that while immigrants who were engaged in the retail of food items were 0.276 times more likely to record a deteriorated livelihood status, those involved in the sale of electronics and accessories were 1.360 times more likely to achieve improved livelihood status (Table 3).

The current evidence from the survey (Table 3) was equally confirmed in the qualitative study. Two of the interviewees who were dealers in electronics and accessories and food products respectively made the following revelations concerning their livelihood status:

My living condition has improved because I earn good money now from my business which was hitherto impossible in my country. I have got a permanent job now as compared to the time I was farming back home. I have improved in terms of my assets too. Aside the assets I possess, I have also made some savings as well and now I think I can feed myself and the family. Will you believe that I have been able to marry through this business? What I will say is that although I do not earn as others, I feel my wellbeing is better now than before and I thank God for that [38-year old dealer in electronics and accessories from Togo].

The second interviewee who dealt in food items made these remarks:

Trading in food items is relatively risky and less profitable unlike those engaged in the sale of durable goods. I record a lot of food rots especially anytime my food items are kept for long. Two other challenges facing my business is that while some of the items are seasonal I also encounter storage-related problems. I really do not make enough money from my business and that has actually affected my living conditions. I don't have the financial capital otherwise I would have changed my line of business. My colleagues who have the money and sell other products like plastic bowls better their lots than those of us who retail perishable items. [45-year old interviewee from Niger]. 
These variations in the livelihood status of the immigrant traders in relation to the types of wares sold underpin the fundamental assumptions of the conceptual framework for the study (Fig. 1) that the type of livelihood activities immigrants undertake at destination have the proclivity to influence their livelihood status. Moreover, these exposés from both the qualitative and quantitative study where itinerant traders of electronics and accessories attained the highest livelihood status further buttressed the evidence put forward by Rogerson (1999) and Agergaard and Thao Thi (2010) that itinerant traders of durable products like hardware, electronics and accessories generally earn higher and have relatively secured and improved livelihoods standards as compared to vendors of other products such as food-related items.

The immigrants' duration in their business had significant influence on the indicators of their livelihood status (Table 3). Immigrants who were involved in their itinerant retail businesses for shorter periods (1-4 years) were 0.670 and 0.485 times less likely to achieve improved job security and food security respectively as compared to those who were engaged in their trading activities for long ( $>=9$ years). It was again realized that immigrant traders who were involved in their itinerant retail businesses for 5-8 years were 0.593 times less likely to accumulate sufficient household assets as compared to the reference category. In general, the length of time the immigrants spent in their business operations had a statistically significant effect on their overall livelihood status (Table 3). This evidence reinforces findings by Hunters and Skinner (2001) in Durban, South Africa where over half of immigrant retailers who were engaged in their business transactions for a considerable period reported an improvement in their economic and social lives. This suggests that in assessing the livelihood status of migrants the time spent in their work is key when assessing their livelihood status. The improvement in the livelihood status of some immigrant traders across the key indicators of their livelihood status (Table 3) conform to findings by Waddington (2003) and Rigg et al. (2014) that most migrants used migration as a strategy to accumulate sufficient income for productive investment, moderate vulnerabilities to shocks and also enhanced their social status.

\section{Conclusions and implications}

The study analysed the livelihood activities of itinerant West African migrant traders who were permanent residents in the AMA of Ghana. Based on the major findings, the following conclusions and implications are drawn. The immigrants were generally young unmarried males from Niger and the majority of them were without formal education (Table 1). The dominant trading activity undertaken among the immigrants was itinerant vending of foot wears/leather belts/bags. Significant variations were found between the immigrants' background characteristics and their livelihood status (Table 3). Nevertheless, male itinerant immigrant traders and those who were older including those involved in the sale of electronics and accessories were more likely to have improved livelihood status. The study concludes that although itinerant trading in the AMA offered an opportunity for many itinerant immigrant traders to earn a living and reduce their socio-economic vulnerabilities, it was found that young females and those who were engaged in the sale of food-related items were less likely to achieve improved livelihood status (Table 3) perhaps due to excessive and unfair competition from their male counterparts and the risk usually associated with the marketing of food items. 
In accordance with the key findings, it is recommended itinerant West African immigrant traders should consider investing more of their resources in the sale of electronics and accessories. This is because that line of business as revealed in Table 3 has the highest potential of guaranteeing secured and improved livelihood. Meanwhile, any form of business support aim at improving the living conditions of itinerant West African migrant traders in the AMA should be focussed on young female itinerant traders and those involved in the sale of food items. It is, however, imperative to state that the improvement in the livelihood status of some of the immigrant traders exemplified in Table 3 has implications for future outmigration of other West Africans into the country.

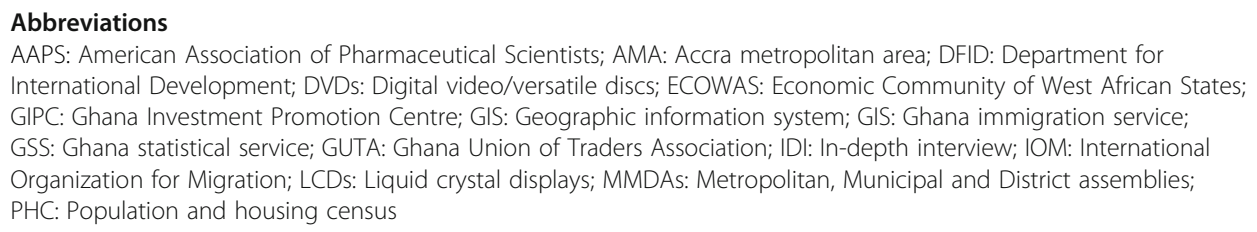

\section{Acknowledgements}

The authors appreciate the effort made by all opinion leaders in the study communities who out of their busy schedules made this research work a success by paving the way for the research work to be carried out without a hitch.

\section{Funding}

This study was self-financed by the authors. That is, no form of assistance was received from anybody or institution.

\section{Availability of data and materials}

The datasets generated and/or analysed during the current study are not publicly available because the data were mainly obtained from the field through a survey and in-depth interviews. However, the data are available from the corresponding author on reasonable request.

\section{Authors' contributions}

Author EY and AT designed the study, performed the statistical analysis, wrote the protocol, and wrote the first draft of the manuscript. Author EY, AT and AK managed the analyses of the study and managed the literature searches. All authors read and approved the final manuscript.

\section{Competing interests}

The authors declare that they have no competing interests.

\section{Publisher's Note}

Springer Nature remains neutral with regard to jurisdictional claims in published maps and institutional affiliations.

\section{Author details}

${ }^{1}$ Department of Governance and Development Management, Faculty of Planning and Land Management, University for Development Studies, Wa, Ghana. ${ }^{2}$ Department of Population and Health, College of Humanities and Legal Studies, University of Cape Coast, Cape Coast, Ghana.

Received: 29 August 2018 Accepted: 27 November 2018

Published online: 10 January 2019

\section{References}

Adepoju, A. (2005). Patterns of Migration in West Africa. In T. Manuh (Ed.), At Home in the World? International Migration and Development in contemporary Ghana and West Africa. Accra: University of Ghana Press.

Agergaard, J., \& Thao Thi, V. (2010). Mobile, flexible, and adaptable: Female migrants in Hanoi's informal sector. Population, Space and Place. https://doi.org/10.1002/psp.622.

Ajavon, J. (2014). Trading Activities of Chinese Migrants in the Central Business District (CBD) of Accra. In Partial Fulfillment of the Requirements for the Award of a Master of Arts Degree in Migration Studies. Legon: Thesis Submitted to the School of Graduate Studies, University of Ghana.

Akinjogbin, L. A. (1980). The economic foundation of Oyo Empire: Economic and Social History. Ile-Ife: University of Ife, Press. Akyeampong, E. K. (2006). Race, identity and citizenship in black Africa: The case of the Lebanese in Ghana. Africa, 76(3), 297-323.

American Association of Pharmaceutical Scientists [AAPS]. (n.d.). AAPS Planning Education Toolkit, The Informal Economy. Arlington: AAPS. 
Anarfi, J. K., Appiah, E. N., \& Awusabo-Asare, K. (1997). Livelihood and the risk of HIV/AIDS infection in Ghana: the case of female itinerant traders. Health Transition Review, 7, 225-242.

Anarfi, J. K., Kwankye, S. O., Ofosu-Mensah, A., \& Tiemoko, R. (2003). Migration from and to Ghana: A Background Paper. December 2003, DRC Working Paper C-4.

Aniegye, N. S. (2012). Settling in and holding on: Socio-economic history of northern traders and transporters in Accra's Tudu, 1908-2008. Leiden: Africa Studies Centre.

Antwi-Bosiakoh, T. (2009). Adjustment, Integration and Development Impacts of Nigerian Migrant Associations in Accra, Ghana. Accra/Legon: Department of Sociology, University of Ghana.

Antwi-Bosiakoh, T. (2016). Nigerian immigrant entrepreneurs in contemporary Ghana: Insights on locational/sectoral niches and inter-generational (dis) continuities. Urban Forum, 28, 143-163.

Awumbila, M. (2017). Drivers of migration and urbanization in Africa: Key trends and issues. Background paper prepared for UN expert group meeting on sustainable cities, human mobility and international migration 7-8, September 2017. New York: UN.

Awumbila, M., Manuh, T., Quartey, P., Tagoe, C., \& Bosiakoh, T. (2009). Ghana migration country paper: trends, issues, and emerging research gaps. Legon: Centre for Migration Studies Technical Paper Series University of Ghana.

Bakewell, O., \& Jónsson, G. (2011). Migration, mobilitéetvillesafricaines. Rapport de synthèse sur le programme de recherche Perspectives africaines sur la mobilité humaine. International Migration Institute, MacAthur Foundation, University of Oxford.

Bebbington, A. (1999). Capitals and capabilities: A framework for analyzing peasant viability, rural livelihoods and poverty. World Development, 27(12), 2021-2044.

Bello-Bravo, J. (2015). Rural-urban migration: A path for empowering women through entrepreneurial activities in West Africa. Journal of Global Entrepreneurship Research, 5(1), 9.

Cahn, M. (2002). Sustainable livelihoods approach: concept and practice. Massey University, 20-12. Retrieved from www.devnet. org.nz/2002/papers/Cahn_Mirandapdf on 5/10/2016.

Carney, D. (1998). Sustainable rural livelihoods: What contribution can we make? London: Department for International Development.

Cerase, F. P. (1974). Migration and social change: Expectations and reality: A case study of return migration from United States to southern Italy. International Migration Review, 16(8), 245-262.

Chambers, R., \& Conway, G. (1992). Sustainable Rural Livelihoods: Practical Concepts for the 21st Century. IDS Discussion Paper 29. Brighton: Institute of Development Studies.

Chowdhury, I. A., Haque, N., Kamal, M. M., Islam, T., Khan, M. M., Islam, M. N., \& Uddin, I. (2012). Internal migration and socioeconomic status of migrants: A study in Sylhet City, Bangladesh. American Journal of Human Ecology, 1(4), 123-133.

Daskon, C., \& Binns, T. (2009). Culture, tradition and sustainable rural livelihoods: Exploring the culture-development interface in Kandy, Sri Lanka. Community Development Journal, 45(5), 494-517. https:/doi.org/10.1093/cdj/bsp019.

De Haan, A., Brock, K., Carswell, G., Coulibaly, N., Seba, H., \& Toufique, K. A. (2000). Migration and livelihoods: Case studies in Bangladesh, Ethiopia and Mali. Brighton, Sussex: Institute of Development Studies.

De Haas, H. (2006). Migration, remittances and regional development in southern Morocco. Geoforum, 37(4), 565-580.

De Haas, H. (2009a). Mobility and human development. New York: UNDP.

De Haas, H. (2009b). Migration and development: A theoretical perspective. International Migration Review, 44(1), 227-264.

Debrah, Y. A. (2007). Promoting the informal sector as a source of gainful employment in developing countries: Insights from Ghana. The International Journal of Human Resource Management., 18(6), 1063-1084.

Department for International Development [DFID] (1999). Sustainable Livelihoods Guidance Sheets. Accessed from http:// www.eldis.org/vfile/upload/1/document/0901/section2.pdf on 3/7/2017.

Duffield, M. (2010). The liberal way of development and the development-security impasse: Exploring the global life-chance divide. Insecurity Dialogue, 41(1), 53-76.

Eades, J. S. (1994). Strangers and traders: Yoruba migrants, markets and the state in Northern Ghana. Trenton: Africa World Press Incorporated.

ECOWAS Commission (2014). Promoting labour mobility through regional cooperation: The case of ECOWAS. Workshop on Strengthening the collection and use of international migration data for development, Addis, November 18-22, 2014.

Ellis, F. (2000). Rural livelihoods and diversity in developing countries. England: Oxford University press.

Fadayomi, T., Fayomi, O. O., \& Adejumo, G. O. (2014). Issues of south-south migration: A case study of Nigerian diasporas in Ghana. Developing Country Studies, 4(10), 167-175.

Fawcett, J. T., \& Arnold, F. (1987). The role of surveys in the study of international migration: An appraisal. International Migration Review, 21(4), 1523-1540.

Ghana Statistical Service [GSS]. (2012). 2010 Population and Housing Census: Summany Report of Final Results. GSS, Accra: Ghana.

Gmelch, G. (1980). Return migration. Annual Review of Anthropology, 9(1), 135-159.

Gough, K. V., \& Langevang, T. (2016). Introduction: youth entrepreneurship in sub-Saharan Africa. In K. V. Gough \& T. Langevang (Eds.), Young entrepreneurs in sub-Saharan Africa (pp. 1-12). Abingdon, Oxon: Routledge.

GSS. (2013). 2010 Population and Housing Census Report: National Analytical Report. Accra: GSS.

GSS. (2014). 2010 Population and Housing Census: District Analytical Report. Accra Metropolitan, Accra: GSS.

Hart, K. (1973). Informal income opportunities and urban employment in Ghana. Journal of Modern African Studies, 11, 61-89.

Hunter, N., \& Skinner, C. (2001). Foreign Street Traders Working in Inner City Durban: Survey Results and Policy Dilemmas. Research Report No. 49. Durban: School of Development Studies (Incorporating CSDS) University of Natal.

International Labour Organization-ILO. (2002). Decent work and the informal economy. Geneva: ILO.

International Organization for Migration [IOM]. (2013). World migration report, 2013: Migrant Wellbeing and Development. France: IOM.

IOM. (2015). World migration report: New partnerships to manage mobility. Switzerland: IOM.

Konseiga, A. (2005). New patterns of migration in West Africa. Stichproben Vienna Journal of African Studies, 8, 23-46.

Koroma, S., Nimarkoh, J., You, N., Ogalo, V., \& Owino, B. (2017). Formalization of informal trade in Africa: Trends, experiences and socio-economic impacts. Accra: FAO, Regional Office for Africa.

Landau, L. B. (2007) Discrimination and development? Immigration, urbanisation and sustainable livelihoods in Johannesburg Development Southern Africa 24 (1):61-76 
Little, P. D. (1999). Selling to Eat: Petty Trade and Traders in Peri-Urban Areas of Sub-Saharan Africa. Research paper prepared for the broadening access and strengthening input market systems-collaborative research support program (BASIS-CRSP). Binghamton: Institute for Development Anthropology.

Lonreco-Lindell, I. (2004). Trade and the Politics of Informalisation in Bissau, Guinea-Bissau. In K. Tranberg Hansen \& M. Vaa (Eds.), Reconsidering Informality, Perspectives from Urban Africa. Uppsala: Nordic Africa Institute.

McDowell, C., \& de Haan, A. (1997). Migration and sustainable livelihoods: A critical review of the literature. IDS Working Paper 65, IDS. Retrieved from https://www.opendocs/ids.ac.uk/ on 30 $0^{\text {th }}$ June, 2016.

Meikle, S., Ramasut, T., \& Walker, J. (2001). Sustainable urban livelihoods: Concepts and implications for policy. Working Paper No. 112. UK: Overseas Development Institute.

Moreda, T. (2012). Vulnerability, land, livelihoods and migration nexus in rural Ethiopia: A case study in South Gondar zone of Amhara regional state. The Hague: International Institute of Social Studies.

Obeng, M. K. M. (2015). Motivations, network and strategies of Ghanaian importers of Chinese products. Legon Journal of Sociology, 5(2), 59-81.

Ohene-Marfo, S. (2014). Immigrant Businesses in Ghana: A Study of the Lebanese in Accra. Thesis Submitted to The University of Ghana, Legon in Partial Fulfillment of the Award of MPhil. Sociology Degree.

Olsen, A. S. W. (2011). Reconsidering west African migration changing focus from European immigration to intra-regional flows. Copenhagen: DIIS Working Paper.

Pallant, J. (2005). SPSS Survival Manual (2nd ed.). Buckingham: Open University Press.

Peberdy, S. (2016). International Migrants in Johannesburg's Informal Economy. SAMP Migration Policy Series No. 71. Waterloo and Cape Town: SAMP.

Peil, M. (1974). Ghana's aliens. The International Migration Review, 8(3), 367-381.

Petersen, E. K., \& Pedersen, M. L. (2010). The sustainable livelihoods approach from a psychological perspective: Approaches to development. Institute of Biology, University of Aarhus, Denmark.

Rigg, J., Nguyen, T. A., \& Luong, T. T. H. (2014). The texture of livelihoods: Migration and making a living in Hanoi. The Journal of Development Studies, 50(3), 368-382.

Roever, S., \& Linares, A. L. (2008). Promoting decent work for street vendors: Case report on Lima, Peru. Report for the ILO InFocus Initiative on the Informal Economy.

Rogerson, R. J. (1999). Quality of life and city competitiveness. Urban Studies, 36(5-6), 969-985.

Rouch, J. (1956). Migrations au Ghana. Journal de la Société des Africanistes, 26(1), 33-196.

Serbeh, R., Adjei, O. P., \& Yeboah, T. (2015). Internal Migration and Poverty Reduction: Rethinking the Debate on the NorthSouth Movement in Ghana. Journal of Social Sciences, Retrieved from https://doi.org/10.3844/jsssp.2015.

Sjaastad, L. A. (1962). The costs and returns of human migration. Journal of Political Economy, 70(5, Part 2), 80-93.

Skinner, C. (2008). Street trade in Africa: A review. Manchester: Women in Informal Employment: Globalising and Organising.

Songsore, J. (2011). Regional development in Ghana: the theory and the reality. Accra: Woeli Publishing Services.

Stenou, K. (2004). UNESCO and the issue of cultural diversity: Review and strategy, 1946-2004. USA: UNESCO.

Tanle, A. (2010). Livelihood status of migrants from the northern savannah zone resident in the Obuasi and Techiman Municipalities. Cape Coast: A Ph. D Thesis submitted to the Department of Population and Health, University of Cape Coast.

Tanle, A. (2014). Assessing livelihood status of migrants from northern Ghana resident in the Obuasi municipality. GeoJournal, 79, 577-590.

Tanle, A. (2015). Towards an integrated framework for analysing the links between migration and livelihoods. NorskGeografiskTidsskrift-Norwegian Journal of Geography, 69(5), 257-264.

Thorsen, D. (2012). Children working in the urban informal economy: Evidence from West and Central Africa. Dakar: UNICEF.

Turner, S., \& Oswin, N. (2015). Itinerant livelihoods: Street vending-scapes and the politics of mobility in upland socialist Vietnam. Singapore Journal of Tropical Geography, 395-410.

United Nations [UN]. (2017). International migration report. New York: UN.

United Nations Development Programme [UNDP]. (2009). Human development report 2009 -overcoming barriers: Human mobility and development. New York: UNDP.

Waddington, J. (2003). What do representatives think of the practices of European works councils? Views from six countries. European Journal of Industrial Relations, 9(3), 303-325.

World Bank. (2017). Migration and Remittances: Recent Developments and Outlook. Special Topic: Global Compact on Migration, Migration and Development Brief No. 27. Germany/Sweden: World Bank Group.

Yaro, J. A. (2008). Migration in West Africa: Patterns, Issues and Challenges. Accra: Centre for Migration Studies at the University of Ghana.

Yendaw, E. (2013). Does international migration represent a mechanism for status enhancement or status loss? A study of international return migrants to Ghana. Journal of International Business and Economics, 1(1), 1-19. 